\title{
Enteral feeding as sole treatment for Crohn's disease: controlled trial of whole protein $v$ amino acid based feed and a case study of dietary challenge
}

\author{
A H Raouf, V Hildrey, J Daniel, R J Walker, N Krasner, E Elias, J M Rhodes
}

Abstract

A controlled trial was performed to compare enteral feeding with either an amino acid based feed or a whole protein feed as sole treatment for active Crohn's disease. Twenty four patients were studied (nine with ileal, 11 with ileocolonic, and four with colonic disease). Both feeds proved effective; nine of 13 patients randomised to receive the amino acid based feed were in clinical remission within three weeks as defined by a simple activity index compared with eight of 11 treated with the whole protein feed. Patients in clinical remission were then crossed over onto the other feed. None of the six patients who were changed to the whole protein feed relapsed over the subsequent three week period compared with three of seven patients who were changed to the amino acid based feed. In responders the median serum $C$ reactive protein concentration fell from $21 \mathrm{mg} / 1$ (range 9-82) on entry to $6 \mathrm{mg} / \mathrm{l}$ (range 3-19) at six weeks. Seven patients relapsed within eight months of starting solid food (mean 3.7 months), while nine were still in remission (follow up period 3-9 months, median six months). Detailed studies of staged reintroduction of food and permitted food additives were carried out over a four year period in a patient with extensive stricturing small bowel Crohn's disease who had been brought into remission by open treatment with enteral feeding. Carrageenan, other permitted emulsifiers, bread, meat, potatoes, oranges, refined sugar, dairy produce, flour, and rice were all reintroduced without any objective ill effect, but green vegetables provoked a clinical and biochemical relapse within one week of introduction. Remission was rapidly achieved by switching back to the enteral feed but reintroduction of the low residue diet that had been previously tolerated produced a brisk relapse. Clinical and biochemical remission was again achieved by a return to the enteral feed but a relapse again occurred with reintroduction of the low residue diet. These studies confirm the therapeutic effect of enteral feeding in Crohn's disease. This effect does not seem to be due to avoidance of whole protein, but the very low residue of chemically defined enteral feeds may be important, particularly in patients with intestinal strictures.
There is increasing evidence that a good therapeutic response can be achieved in Crohn's disease by dietary treatment alone. Initially this was thought to be achievable only by complete 'bowel rest,' which was accomplished by intravenous feeding and avoidance of enteral food. ${ }^{12}$ Since then it has been shown that bowel rest is not essential ${ }^{34}$ and that equally good results can be achieved by enteral feeding using a carefully defined 'elemental' feed consisting mainly of amino acids and carbohydrate..$^{5-9}$ It is not clear how enteral feeds achieve their therapeutic effect. Although amino acid based feeds are presumably hypoallergenic, in a recent trial good results were reported with a feed containing whole egg albumin. ${ }^{10}$ Furthermore, the chronic inflammation that typifies the inflammatory response in Crohn's disease seems unlikely to be the result of an allergic response. Trials in which a beneficial effect has been reported when a normal diet is supplemented with either intravenous $^{3}$ or enteral ${ }^{11}$ feeding suggest that the therapeutic effect may be the result of improved nutrition rather than exclusion of any component of the normal diet, though it is also possible that the dietary supplement suppresses the appetite and results in reduced consumption of the normal diet.

To try to clarify some of these issues we performed two studies: (i) a randomised controlled trial comparing enteral feeding with an amino acid based feed with a whole protein based feed and (ii) a protracted (four year) study of staged reintroduction of components of a 'normal' diet in a patient with extensive small bowel Crohn's disease after induction of remission by enteral feeding.

\section{Methods}

TRIAL OF WHOLE PROTEIN V AMINO ACID BASED ENTERAL FEEDING

\section{Patients studied}

Twenty four patients with active Crohn's disease were studied (nine with ileal, 11 with ileocolonic, and four with colonic disease). These patients all had active disease as defined by the Bristol simple index ${ }^{12}$ and by the more complex index described by Van Hees $e t a l,{ }^{13}$ and all had a raised serum $C$ reactive protein concentration

\author{
Correspondence to: \\ Dr J M Rhodes, Departmen \\ of Medicine, Liverpool \\ Liverpool L69 3BX \\ Accepted for publication \\ 3 July 1990 \\ University Department of
Medicine and Walton
Hospital, Liverpool
A H Raouf
V Hildrey
R J Walker
N Krasner
J M Rhodes
Departments of Medicine \\ and Dietetics, Quee \\ Elizabeth Hospital, \\ Birmingh \\ E Elias
}


$(>6 \mathrm{mg} / \mathrm{l})$. The median simple index on entry was 12.5 (range 8-24), the median Van Hees score on entry was 188 (range 142-302), and the median serum $C$ reactive protein concentration on entry was $26.5 \mathrm{mg} / \mathrm{l}$ (range 6-128). Five of the patients were having their first attack of Crohn's disease.

Three of the patients were receiving sulphasalazine on entry to the study and this was continued unchanged. Five patients were receiving corticosteroids (prednisolone $2 \cdot 5-20 \mathrm{mg} /$ day, median $12.5 \mathrm{mg} /$ day) and of these, two were randomised to receive the amino acid based feed as initial treatment and three to receive the whole protein feed. Patients were excluded from the study if steroid treatment had been started or altered within the four weeks before the trial began. No change in corticosteroid treatment was made during the trial.

\section{Experimental design}

Patients were randomised to receive either an amino acid based enteral feed (EO28, Scientific Hospital Supplies, Liverpool, UK) or a whole protein (non-hydrolysed milk protein) enteral feed (Triosorbon, E Merck Ltd, Alton, UK) as their sole food intake. Patients who had gone into clinical remission within three weeks as assessed by the simple index were then crossed over to the alternative enteral feed. Patients who had failed to show any improvement on two consecutive weekly assessments were withdrawn from the trial and treated openly. The study was approved by South Sefton District Ethical Committee.

\section{Enteral feeding}

Enteral feeding was given under careful dietetic supervision and aimed to achieve a dietary intake of $80 \mathrm{~g} /$ day of protein and 2000 calories. The initial week of enteral feeding was carried out under careful supervision in hospital and the patient was then allowed home. The enteral feeds were drunk from a glass. The EO28 had been flavoured orange by the manufacturers and the Triosorbon was flavoured to the patient's preference using Nesquick (Nestlé, UK).

\section{Monitoring}

Patients were seen weekly throughout the study by both a clinician and a dietitian. Weekly estimation of serum albumin and erythrocyte sedimentation rate was performed to allow calculation of the Van Hees activity index. Activity was also assessed according to the Bristol 'simple' activity index and serum $\mathrm{C}$ reactive protein concentration. Clinical remission was defined as a simple index score of 4 or less, as this has been shown to correspond to a Crohn's disease activity index score of approximately $150 .^{12}$

STAGED REINTRODUCTION OF FOOD COMPONENTS, PERMITTED EMULSIFIERS, AND CARRAGEENAN IN A PATIENT WITH SMALL BOWEL CROHN'S DISEASE The patient was a 32 year old white man with a five year history of extensive stricturing small

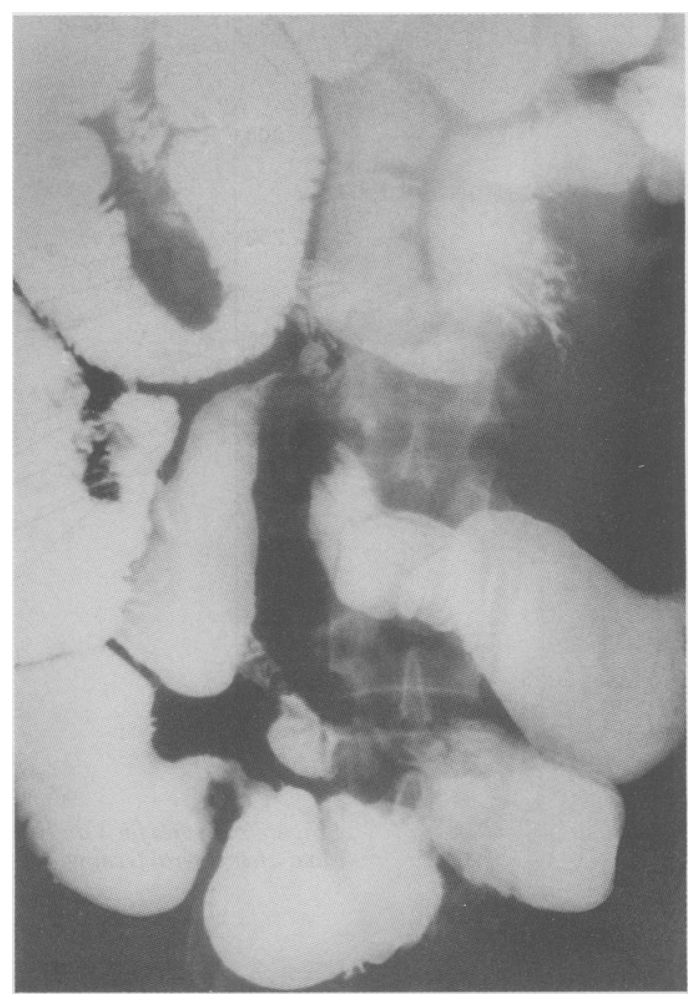

Figure 1: Small bowel barium enema study showing multiple small bowel strictures in the patient studied by staged reintroduction of food components after remission had been induced by enteral feeding.

intestinal Crohn's disease (see Fig 1). Throughout the five years he had been receiving oral prednisolone for all but one month in an average dose of $15 \mathrm{mg} /$ day. The serum albumin concentration had fluctuated between 21 and $36 \mathrm{~g} / 1$ and his weight between 56 and $79 \mathrm{~kg}$. At the time of entry into the study he had been off work for two months because of abdominal pain and malaise. The serum albumin concentration was $24 \mathrm{~g} / \mathrm{l}$, weight $61 \mathrm{~kg}$, and he was receiving prednisolone $10 \mathrm{mg} /$ day. He was started on enteral feeding with an amino acid based feed (Vivonex, Mead Johnson, UK), avoiding all other food, and he started to feel better within the first week. Corticosteroid treatment was tailed off completely over the next three weeks and improvement was maintained. No drug treatment was used throughout the remainder of the four year study period. The serum albumin concentration rose to $32 \mathrm{~g} / \mathrm{l}$ (its highest value for over two years) and the patient was able to return to work. He continued to lose weight, however, probably because he was able to take in only 1800 calories per day ( $35 \mathrm{~g}$ protein). He was changed initially onto a whole protein feed (Ensure Plus, 2400 calories and $110 \mathrm{~g}$ protein/day) and then after a further four weeks was changed to a different whole protein feed (Triosorbon, Merck, UK) containing 2800 calories and $113 \mathrm{~g}$ protein/day in order to give him a diet that was free from sucrose and carrageenan. With this as his only source of food he made excellent progress, the serum albumin concentration rising to $39 \mathrm{~g} / \mathrm{l}$ and his weight increasing to $68 \mathrm{~kg}$. At this stage he gave informed consent to undergo a series of prolonged challenges with various components of a 'normal' diet including carrageenan, other permitted emulsifiers, and sucrose, all factors 


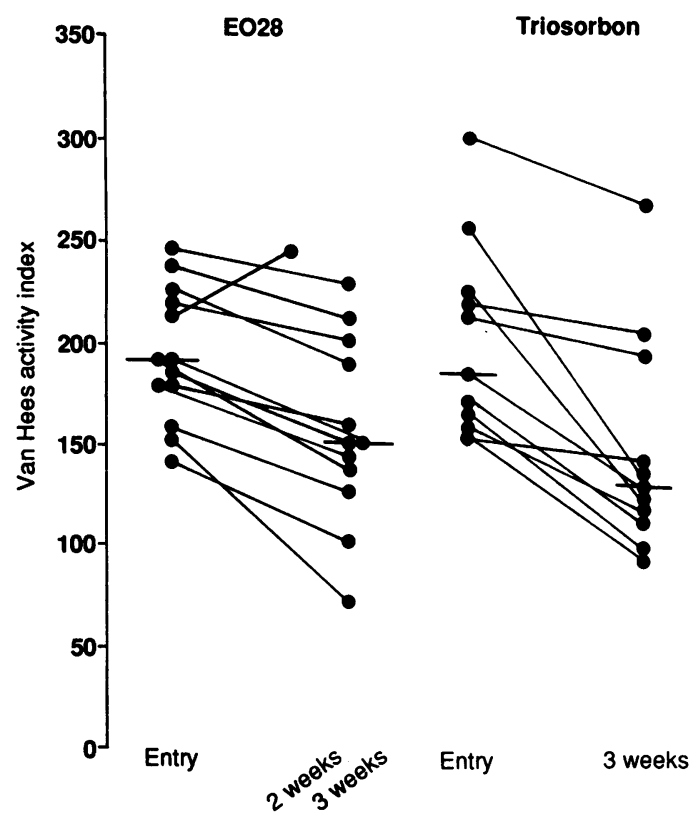

Figure 2: Scores for Van Hees disease activity index before and after enteral feeding. (Horizontal bars denote medians).

that have been incriminated in the aetiology of Crohn's disease. Each dietary component was assessed for one month with the exception of the carrageenan and permitted emulsifiers, which were both assessed over two month periods. The study took four years to complete. With the exception of the carrageenan and emulsifiers, food components were added cumulatively and the intake of the liquid enteral feed gradually reduced with the aim of maintaining a constant calorie and protein intake. His weight and serum albumin concentration were documented at the start and finish of each dietary challenge, abdominal pain or diarrhoea were noted, and an abdominal examination performed. Objective biochemical assessment of disease activity was done initially by faecal chromium excretion after intravenous injection of ${ }^{51}$ chromium as a measure of intestinal protein loss and subsequently by measurement of serum $\mathrm{C}$ reactive protein concentration.

Food grade carrageenan (E407) 2 g/day was kindly supplied by KWR Chemicals (Marine Colloids), UK. The other permitted emulsifiers which were all challenged together comprised polyoxyethylene sorbitan monostearate (Tween 60) $2 \mathrm{~g} /$ day, polyglycerol esters of castor oil (Admul 1403) $0.5 \mathrm{~g} /$ day, and polyglycerol esters of edible fats (Admul 1405 and Admul 1411) 0.5 $\mathrm{g}$ of each per day. These emulsifiers were kindly supplied by Food Industries, UK. The carrageenan and the mixture of permitted emulsifiers were incorporated into lozenges using carob gum as a gelling agent.

\section{Results}

All eleven of the patients randomised to receive the whole protein feed showed an improvement in the Van Hees activity score (initial: mean score 200, median 185, range 151-302; after three weeks: mean score 147 , median 139 , range 95-270; Fig 2), but the improvement in the simple index was more striking (initial: mean
10.6, median 10, range 8-15; after three weeks: $3 \cdot 0,3,0-14$; Fig 3 ), with nine patients going into remission as assessed by this index. The serum $C$ reactive protein concentration fell in nine of 11 patients (initial: mean $41 \mathrm{mg} / \mathrm{l}$, median $24 \mathrm{mg} / \mathrm{l}$, range 9-112 mg/l; after three weeks: $23.3 \mathrm{mg} / \mathrm{l}$, $13 \mathrm{mg} / 1,3-74 \mathrm{mg} / \mathrm{l} ;$ Fig 4$)$. The only patient with a poor response (Van Hees score 215-195, simple index $15-14, C$ reactive protein $61-74 \mathrm{mg} / \mathrm{l}$ ) had colonic disease while the responders included five with ileocolonic disease, four with ileal disease, and one with colonic disease. All eleven tolerated the feed well.

Twelve of the 13 patients who were randomised to receive the amino acid based feed showed some improvement in Van Hees score (initial: mean score 193, median 190, range 142-245; after three weeks: mean score 156, median 151, range 72-230). The same 12 showed appreciable improvement in the simple index (initial: mean 14, median 14, range 6-24; after three weeks: $1 \cdot 8,1,0-6$ ), and $C$ reactive protein (initial: mean $43.1 \mathrm{mg} / \mathrm{l}$, median $29 \mathrm{mg} / \mathrm{l}$, range 9-128 mg/l; after three weeks: $12.5 \mathrm{mg} / 1,8 \mathrm{mg} / 1$, 3-54 mg/l). One patient with colonic disease was withdrawn after two weeks having failed to respond (Van Hees score 216-245; simple index 12-12; C reactive protein $80-203 \mathrm{mg} / \mathrm{l}$ ).

The responses to the two enteral feeds were also analysed according to the percentage improvement in simple index, Van Hees index, and serum $C$ reactive protein using Wilcoxon's rank sum test to compare the response to the two feeds. EO28 resulted in a median improvement in simple index of $91.7 \%$ compared with $86.7 \%$ for Triosorbon ( $p=0.35$, not significant), a median improvement in Van Hees index of $18.5 \%$ compared with $30.0 \%$ for Triosorbon $(\mathrm{p}=\mathbf{0} \cdot 23$, not significant $)$, and a median improvement in $\mathrm{C}$ reactive protein of $58.3 \%$ compared with $57 \cdot 1 \%$ for Triosorbon ( $p=0 \cdot 49$, not significant).

Thirteen of the patients who had attained clinical remission as judged by simple index score then entered a second three week phase of the study in which they changed enteral feeds. Crossover was attempted in a further eight but failed because of poor tolerance of the second enteral feed. Six changed from the amino acid based feed to the whole protein feed. In one of these the changeover was delayed until the patient had received four weeks of the first enteral feed because the simple index at three weeks, although improving (15 to 6), was slightly raised. All six patients continued to improve or maintained their previous improvement when changed over to the whole protein feed (median Van Hees score on crossover 151 (range 72-230), improving to $126(80-171)$ after three weeks; median simple index score on crossover 1 (range 0.5 ), improving to 0 (range $0-1$ ); median $C$ reactive protein on crossover $9.5 \mathrm{mg} / \mathrm{l}$ (range 5-25), improving to $4.5 \mathrm{mg} / \mathrm{l}$ (range 3-6).

Seven patients crossed over from the whole protein feed to the amino acid based feed, and again in one patient crossover was delayed by a week because of high but improving activity indices. Three of the seven deteriorated significantly (Van Hees scores 120-308, 139-175, 141-172; simple index score 3-17, 1-3, 0-16; 


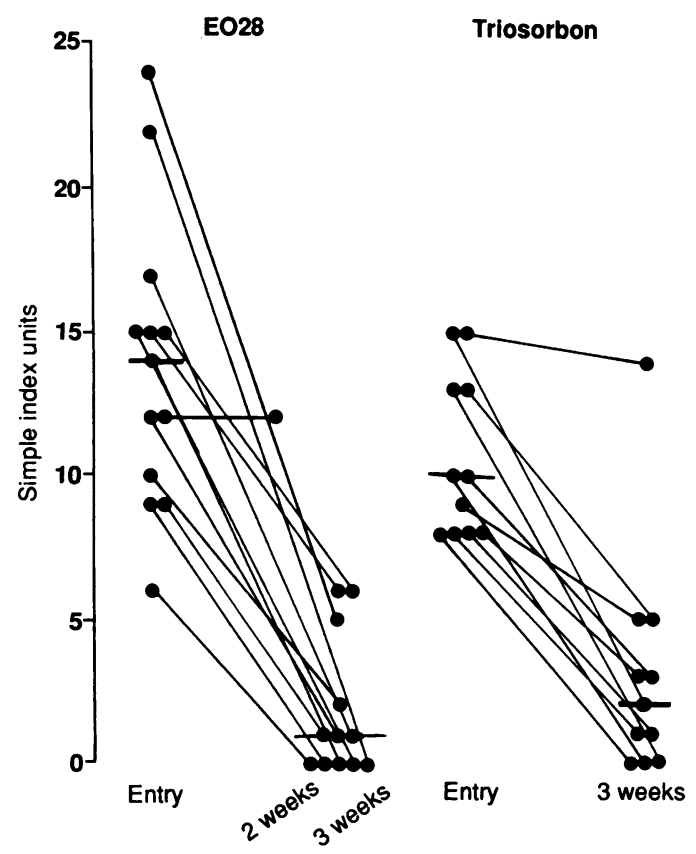

Figure 3: Scores for Harvey/Bradshaw simple index of disease activity before and after enteral feeding.

C reactive protein $3-57 \mathrm{mg} / 1,13-24 \mathrm{mg} / \mathrm{l}, 40-138$ $\mathrm{mg} / \mathrm{l}$ ) while the other four maintained their improvement.

\section{STAGED REINTRODUCTION OF DIETARY} COMPONENTS IN A PATIENT WITH SMALL BOWEL CROHN'S DISEASE

The response to stepwise reintroduction of dietary components after induction of remission with enteral feeding is summarised in Figure 5. The introduction of carrageenan was associated with mild diarrhoea and a weight loss of $3 \mathrm{~kg}$, but the serum albumin concentration continued to

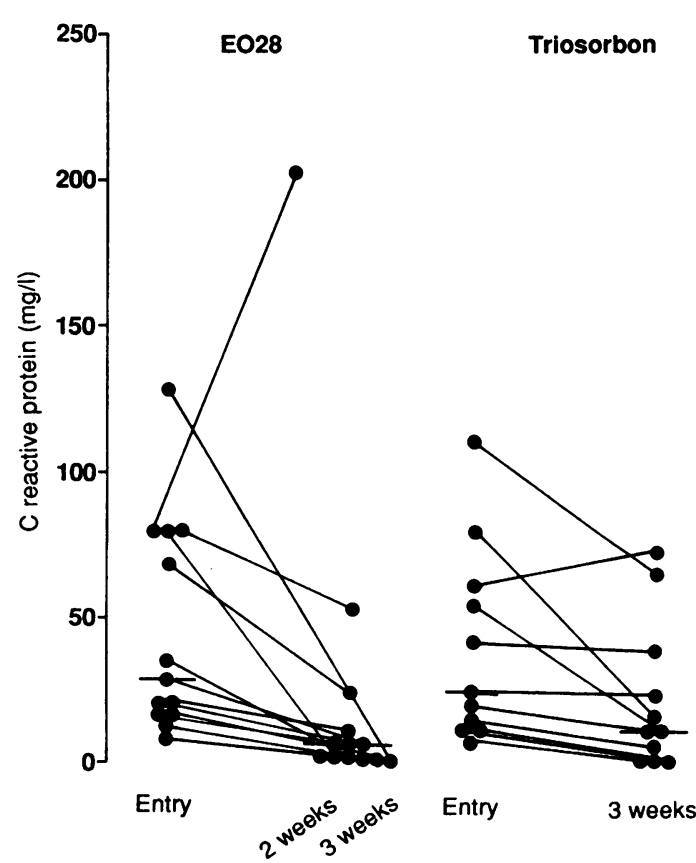

Figure 4: Serum $C$ reactive protein concentration before and after enteral feeding. rise and the faecal chromium excretion fell to normal so it was considered that this could not be taken as conclusive evidence of a relapse of his disease. Carrageenan was stopped after two months and the combination of the other emulsifiers being tested was substituted. Mild diarrhoea and a further $2 \mathrm{~kg}$ weight loss resulted but again without a reduction in the serum albumin concentration, which by this time had reached $40 \mathrm{~g} / \mathrm{l}$, and the faecal chromium excretion fell still further. The emulsifiers were then stopped and normal food components introduced cumulatively at one or two month intervals (see Figure 5). Bread, lamb, potatoes, oranges, refined sugar, chicken, all other meats, dairy produce, flour, and rice were introduced without any problems. Throughout this time he was feeling better than he had done since first presenting with Crohn's disease and was back in full employment. Serum albumin and $\mathrm{C}$ reactive protein concentrations remained normal.

Vegetables were then added (Brussels sprouts, carrots, cauliflower, onions, and green beans) and within one week he was feeling unwell with abdominal discomfort and loss of energy. This was accompanied by an abrupt rise in the serum $C$ reactive protein concentration from $6 \mathrm{mg} / \mathrm{l}$ to $68 \mathrm{mg} / \mathrm{l}$ and a fall in the serum albumin concentration from 38 to $29 \mathrm{~g} / \mathrm{l}$ as well as a $4 \mathrm{~kg}$ weight loss. After three weeks on vegetables all normal food was stopped and he was changed back to the enteral feed (Triosorbon) as his sole food intake. Within one week he was feeling well, the serum C reactive protein concentration falling to normal within two weeks. He was then started back on the low residue diet that he had been taking without problems before the introduction of vegetables in combination with oral metronidazole ( $400 \mathrm{mg}$ three times a day) in the assumption that vegetable residue might be encouraging bacterial overgrowth proximal to his small bowel strictures, but, surprisingly, he relapsed promptly when the low residue diet was reintroduced. The serum $C$ reactive protein concentration agains rose abruptly to $84 \mathrm{mg} / \mathrm{l}$ and he felt generally unwell. Once again he was changed back to enteral feeding (Triosorbon) as the sole food intake and again he was feeling better within a few days, the serum $C$ reactive protein again falling rapidly to normal. One further attempt was made to reintroduce the low residue diet but this provoked a recurrence of abdominal pain, bloating, and malaise associated with a rise in the serum $C$ reactive protein concentration from $6 \mathrm{mg} / \mathrm{l}$ to $44 \mathrm{mg} / \mathrm{l}$.

A small bowel barium meal performed at this time showed the presence of multiple small bowel strictures (Fig 1) with little change from the previous $x$ ray films taken four years earlier before the study began. A laparotomy was performed at which multiple short strictures were found and six stricturoplasties were carried out. Histology from one of the strictured areas showed non-specific inflammatory changes without granulomas. He tolerated a normal diet after the stricturoplasties but continued to have intermittent abdominal discomfort and required a further period of enteral feeding before his serum albumin concentration and weight returned to normal. 


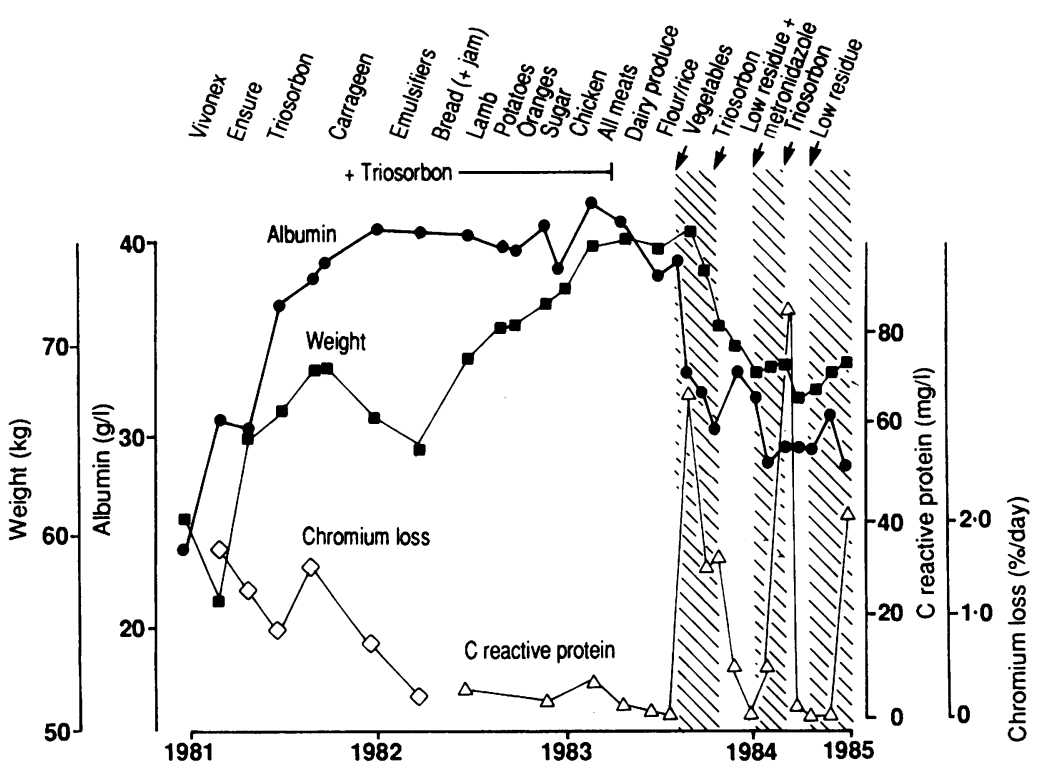

Figure 5: Effect of dietary challenge and staged reintroduction of dietary components on weight, serum albumin concentration, gastrointestinal protein loss (faecal chromium loss), and serum $C$ reactive protein concentration in a patient with multiple small bowel Crohn's disease strictures. Hatched areas denote clinical relapse. the avoidance of whole protein is essential for the therapeutic effect. In the randomised controlled trial reported here good results were achieved in response to treatment both with an amino acid based feed and with a whole protein feed, with no discernible trend favouring either. Dietary treatment was particularly effective as assessed by the simple index, which returned to normal in 18 of 24 patients within three weeks. The Van Hees index was slower to normalise, partly due to the inclusion of weight as a factor in this index but also because Van Hees and colleagues chose to set their upper limit for inactive disease as an index of 100, equivalent to a Crohn's disease activity index of 100, rather than 150 . No clinical index of Crohn's disease activity is totally objective, and the improvement in the serum C reactive protein concentration shown with both forms of enteral feeding gives unequivocal objective evidence of a biochemical response to treatment.

There have been surprising differences in the reported responses to different enteral feeds in Crohn's disease. Good results have been reported with Enteral $400,{ }^{14}$ which, like Triosorbon, is a whole protein feed, mixed results with the whole protein feed Ensure, ${ }^{15} 16$ and poor results with the whole protein feed Fortison $^{17}$ and with an oligopeptide feed Peptisorb. ${ }^{18}$ These differences in response to enteral feeds, if real, clearly must be due to some factor other than the presence or absence of whole protein. Carrageenan may be relevant as it is universally used as an emulsifier in feeds that come ready-prepared as a liquid and is absent from the feeds whch are marketed in powder form.

It is therefore important to try to determine whether there are any components of a normal diet that are absent from the therapeutically effective enteral feeds but which might be precipitating factors in Crohn's disease. The chronic nature of the inflammatory infiltrate in Crohn's disease tissue and the fact that it takes up to six weeks for normalisation of the serum $C$ reactive protein concentration in response to dietary treatment make it unlikely that challenge studies will give clearcut results unless each change of food is maintained for at least one month. This meant that a lengthy study was necessary to assess the main dietary components. We were fortunate to have the help of a stoical and well motivated patient, who had achieved a successful remission of disease with dietary treatment after protracted ill health.

Carrageenan, which is widely used in the food industry as an emulsifier, was the first food component to be tested. Marcus and Watt showed that oral administration of degraded (low molecular weight) carrageenan resulted in caecal inflammation within three to five months in rabbits, guinea pigs, and primates. ${ }^{19}$ Onderdonk and colleagues have studied this model further and shown that metronidazole prophylaxis prevents ulceration if given together with the carrageenan ${ }^{20}$ and that germ free guinea pigs do not develop carrageenan colitis. ${ }^{21}$ The presence of certain strains of Bacteroides vulgatus seems to be important in the development of the intestinal inflammation and granulomas may be a feature. ${ }^{22}$ (iii) 'bowel rest' posibly in reduced intestinal bacterial content as a result of a low residue intake; (iv) the avoidance of some trigger factor such as a food additive that is present in the patient's normal diet.

Most studies of enteral feeding in Crohn's disease have used amino acid based enteral feeds. These feeds are relatively unpalatable and expensive, so it was important to assess first whether 
No harmful effect has been shown, however, when food grade carrageenan has been fed to animals. ${ }^{23}$ Carrageenan and the combination of permitted emulsifiers with which our patient was challenged both caused mild diarrhoea but neither was associated with a convincing relapse of Crohn's disease, and in particular there was no increase in intestinal protein loss. Both were tried for periods of two months, but it could be argued that an even longer challenge is necessary to exclude with certainty any harmful effect.

Sucrose was then challenged on the grounds that several epidemiological studies have shown a high intake of refined sugar before illness in patients with Crohn's disease. ${ }^{24}$ This was well tolerated by our patient, however. Other components of a normal diet were then introduced at monthly intervals with no ill effect until green vegetables were introduced. These caused a prompt relapse of symptoms. It should be remembered that the patient had multiple tight small bowel strictures. Further barium studies performed after the patient had been in remission for several months on enteral feeding showed persistence of these strictures, which were presumably fibrous. It is not surprising that vegetable fibre might cause obstructive symptoms but it is notable that these were accompanied by a systemic biochemical response with a fall in serum albumin and a rise in serum $C$ reactive protein concentrations. After remission had been established by returning to the enteral feed, the patient relapsed promptly when we introduced the low residue diet that he had had without problems before the introduction of vegetables. We thought that some vegetable matter might be caught behind intestinal strictures and that the modest increase in residue was sufficient either to cause further obstruction or to encourage bacterial overgrowth proximal to the strictures.

It seems most likely that the effects of diet on Crohn's disease are multifactorial. In patients with tight intestinal strictures the residue content of the diet, particularly the vegetable fibre content, is clearly important. The good results obtained in some studies by supplementing rather than replacing the normal diet with an enteral formula feed suggest that there is probably also a nutritional effect. Possible candidates for this effect include selenium, ${ }^{25}$ zinc, ${ }^{26}$ and antioxidant vitamins. ${ }^{27}$ Finally, the possibility that there may be a harmful factor in the 'normal' diet remains. Although carrageenan challenge had no convincing effect in this study, the results of feeding degraded carrageenan to animals bear many striking similarities to Crohn's disease, and from the time course of these studies it seems likely that a dietary challenge lasting several months would be needed before carrageenan can be completely exonerated.

Enteral feeding with formula diets undoubtedly has a therapeutic effect in Crohn's disease. These feeds do not have to be free from whole protein to be effective. Further studies are needed to determine the mechanisms of the therapeutic effect.

Part of the funding for this study was provided by E Merck Ltd, Alton, UK.

1 Fischer JE, Foster GS, Abel RM, Abbott WM, Ryan JA. Hyperalimentation as primary therapy for inflammatory bowel disease. Am f Surg 1973; 125: 165-75.

2 Vogel CM, Corwin TR, Baue AE. Intravenous hyperalimentation in the treatment of inflammatory diseases of the bowel. Arch Surg 1974; 108: 460-7.

3 Lochs H, Meryn S, Marosi L, Ferenci P, Hortnag H. Has total bowel rest a beneficial effect in the treatment of Crohn's disease? Clin Nutr 1983;2:61-4.

4 Payne-James JJ, Silk DBA. Total parenteral nutrition as primary treatment in Crohn's disease - RIP? Gut 1988; 29: $1304-8$.

5 Voitk AJ, Echave V, Feller JH, Brown RA, Gurd FN. Experience with elemental diet in the treatment of inflammatory bowel disease. Is this primary therapy? Arch Surg 1973; 107: 329-33.

6 Rocchio MA, Mocha C, Haas KF, Randall HT. Use of chemically defined diets in the management of patients with acute inflammatory bowel disease. Am F Surg 1974; 127: 469-75.

7 Axelsson C, Jarnum S. Assessment of the therapeutic value of an elemental diet in chronic inflammatory bowel visease. Scand $\mathcal{F}$ Gastroenterol 1977; 12: 89-95.

8 O'Morain C, Segal AW, Levi AJ. Elemental diets in the treatment of acute Crohn's disease. $B M F$ 1980; 281 : treatment

9 Logan RF, Gillon J, Ferrington C, Ferguson A. Reduction of gastrointestinal protein loss by elemental diet in Crohn's disease of the small bowel. Gut 1981; 22: 383-7.

10 Greenberg GR, Fleming CR, Jeejeebhoy KN, Rosenberg IH, Sales D, Tremaine WJ. Controlled trial of bowel rest and nutritional support in the management of Crohn's disease. Gut 1988; 29: 1309-15.

11 Harries AD, Jones LA, Danis V, Fifield R, Heatley RV Newcombe RG. Controlled trial of supplemented oral nutrition in Crohn's disease. L ancet 1983; i: 887-90.

12 Harvey RF, Bradshaw JM. A simple index of Crohn's disease activity. Lancet 1980; i: 514.

13 Van Hees PAM, Van Elteren PH, Van Lier HJJ, Van Tongeren JHM. An index of inflammatory activity in patients with Crohn's disease. Gut 1980; 21:279-86.

14 Park RHR, Galloway A, Danesh BJZ, Russell RI. Double blind trial comparing elemental and polymeric diet as primary therapy for active Crohn's disease. Gut 1989; 30: A1453.

15 Imes S, Pinchbeck B, Dinwoodie A, Walker K, Thomson ABR. Effect of Ensure ${ }^{R}$, a defined formula diet, in patients with Crohn's disease. Digestion 1986; 35: patients

16 Ginsberg AL, Albert MB. Treatment of patient with severe steroid-dependent Crohn's disease with nonsevere steroid-dependent Crohn's disease with nonetiologic dietary factor. Dig Dis Sci 1989; 34: 1624-8.

17 Giaffer MH, North G, Holdsworth CD. Controlled trial of polymeric versus elemental diet in treatment of active Crohn's disease. Lancet 1990; 335: 816-9.

18 Lochs H, Steinhardt HJ, Klaus-Wenz B, Bauer P, Malchow $H$. Enteral nutrition versus drug treatment for the acute phase of Crohn's disease. Study IV. Gastroenterology 1988; 94: A267.

19 Marcus R, Watt J. Seaweeds and ulcerative colitis in laboratory animals Lancet 1969 ; ii: 489-90.

20 Onderdonk AB, Hermos JA, Dzink JL, Bartlett JG Protective effect of metronidazole in experimental urotective effect of metronidazole in experim

21 Onderdonk AB, Franklin ML, Cisneros RL. Production of experimental ulcerative colitis in gnotobiotic guinea pigs with a simplified microflora. Infect Immun 1984; 32: pigs with

22 Onderdonk AB, Bronson $R$, Cisneros $R$. Comparison of Bacteroides vulgatus strains in the enhancement of experimental ulcerative colitis. Infect Immun 1987; 55: $835-6$.

23 Benitz KF, Goldberg L, Coulson F. Intestinal effects of carrageenan in the rhesus monkey (Macaca mulatta). Food and Cosmetics Toxicology 1973; 11: 565-75.

24 Mayberry JF, Rhodes J. Epidemiological aspects of Crohn's disease. Gut 1984; 25: 886-99.

25 Hinks LJ, Inwards KD, Lloyd B, Clayton B. Reduced concentrations of selenium in mild Crohn's disease. concentrations of selenium in

26 Solomons NW, Rosenberg IH, Sandstead $\mathrm{HH}$, Vo-Khactu KP. Zinc deficiency in Crohn's disease. Digestion 1977; 16: 87-95.

27 Pettit SH, Irving MH. Does local intestinal ascorbate deficiency predispose to fistula formation in Crohn's disease. Dis Colon Rectum 1987; 30: 552-7. 